\title{
Numerical simulation of the heavy rainfall caused by a convection band over Korea: a case study on the comparison of WRF and CReSS
}

\author{
Eun-Soon Im $\cdot$ So-Ra In $\cdot$ Sang-Ok Han
}

Received: 21 December 2012/ Accepted: 5 July 2013/Published online: 23 July 2013

(C) The Author(s) 2013. This article is published with open access at Springerlink.com

\begin{abstract}
This study investigates the capability of two numerical models, namely the Weather Research and Forecasting (WRF) and Cloud Resolving Storm Simulator (CReSS), to simulate the heavy rainfall that occurred on September 21, 2010 in the middle of the Korean peninsula. This event was considered part of the typical rainfall caused by intense quasi-stationary convection band, leading to a large accumulated rainfall amount within a narrow area. To investigate the relevant characteristics of this heavy rainfall and the feasibility of the numerical models to simulate them, the experiments using both numerical models were designed with a focus on Korea with a horizontal grid spacing of $2 \mathrm{~km}$. The initial and later boundary conditions were interpolated using the output of the mesoscale model of Japan Meteorological Agency and integration spanned the 24-h period from 2100 UTC on September 20, 2010 when the rainfall started in the Yellow Sea. Generally, the spatial distribution and temporal evolution of the rainfall simulated by CReSS are closer than those of the WRF to the in situ observations (655 stations). The WRF simulation reveals the deficiency in capturing the unusual stagnant behavior of this event. The spatial and vertical patterns of reflectivity are consistent with the rainfall pattern, supporting that strong reflectivity coincides with the convective activity that accompanies excessive rainfall. The thermodynamic structure is the main driver of the different behavior between both simulations. The higher equivalent potential temperature, deep moist absolutely unstable layer and strong veering wind shear seen in the CReSS simulation play a role in the development of a favorable environment for inducing convection.
\end{abstract}

Keywords Heavy rainfall · Quasi-stationary convection band · Weather Research and Forecasting (WRF) · Cloud Resolving Storm Simulator (CReSS)

E.-S. Im · S.-R. In · S.-O. Han

National Institute of Meteorological Research, Korea Meteorological Administration, Seoul, Korea

E.-S. Im $(\bowtie)$

Center for Environmental Sensing and Modeling, Singapore-MIT Alliance for Research and Technology (SMART), 1 CREATE Way \#09-03 CREATE Tower, Singapore 138602, Singapore e-mail: eunsoon@smart.mit.edu 


\section{Introduction}

The precipitation of Korea is characterized by distinct seasonal and regional variability. Of particular concern is the frequent occurrence of localized heavy rainfall which pours with high intensity during a short period because it directly causes flash flooding. Based on the classification of the heavy precipitation system over Korea (Lee and Kim 2007), one major type is the heavy rainfall caused by an intense quasi-stationary convection band occupying about $30 \%$. Since the convection band tends to be rapidly developed and shows relevant locality, it is very difficult for accompanied heavy rainfall to be adequately predicted. Furthermore, the quasi-stationary or stagnated behavior of the convection band can sustain the tremendous damage at a certain location because rainfall is accumulated.

Several references in the literature deal with the development mechanism and structure of the convection band accompanying heavy rainfall over Korea based on case studies using observational data and numerical modeling (Sun and Lee 2002; Shin and Lee 2005; Cho and Lee 2006; Kim and Lee 2006; Choi et al. 2011; Yu and Lee 2010; Hong and Lee 2009). Generally, these modeling studies revealed some significant discrepancies between the simulation and observation in both the location and amount of heavy rainfall. In spite of the inherent limitation of numerical models, the physically based simulation results could provide the insight into the structure and evolution of mesoscale processes contributing to heavy rainfall, so that this approach could be alternative way to compensate the insufficient observational data in terms of spatial and temporal coverage (Chen et al. 1999; Choi et al. 2011).

The recent torrential rainfall that occurred on September 21, 2010 in the middle of the Korean peninsula was considered a typical pattern of heavy rainfall caused by a convection band. The daily accumulated rainfall amount and the maximum hourly rain rate in Seoul were $259.5 \mathrm{~mm}$ and $75 \mathrm{~mm}$, respectively, which were highest values ever recorded in late September. However, the Korea Meteorological Administration (KMA) had forecasted 20-60 $\mathrm{mm}$ as the daily rainfall amount. The forecasted results from the National Weather Service (NWS), European Centre for Medium-Range Weather Forecasts (ECMWF), and Japan Meteorological Agency (JMA) were not greatly different with that of KMA (brief press release by KMA). For example, the ECMWF ensemble forecast derived approximately $40 \mathrm{~mm}$ rainfall as the maximum daily rainfall amount in Seoul. These forecast deficiencies highlight the difficulty in using the current operational numerical models to simulate such events accurately. One of the reasons is related to their coarse resolution in capturing the localized convection band (Cho and Lee 2006).

In this study, we attempt to simulate the heavy rainfall that occurred on September 21, 2010 in the middle of the Korean peninsula using two high-resolution non-hydrostatic models, namely Weather Research and Forecasting (WRF) and Cloud Resolving Storm Simulator (CReSS). While WRF has been popularly applied for the case studies of the extreme weather events over Korea, few simulations using CReSS have focused on Korea. Only Lee et al. (2010) applied CReSS to simulate the topographically induced localized intense rainfall over Jeju Island, Korea. In order to examine the performance in capturing the key characteristics of sudden and excessive rainfall along the narrow localized band, the two simulation sets using the different numerical models (WRF and CReSS) are integrated under the same experiment design (boundary condition, domain size and resolution) with fine-scale grid spacing of $2 \mathrm{~km}$ where convective rainfall generation is assumed to be explicitly resolved. Both model results are evaluated by comparison with station-based observation (655 points) in terms of spatial distribution and temporal evolution. Radar reflectivity is also compared to those of simulated results as an indication of 
convective activity. Given the relatively lack of well-known behaviors for the CReSS performance, this study will assist in assessing the feasibility of application of CReSS for the simulation of severe weather events over Korea.

\section{Model description}

The numerical models used in this study are the WRF (version 3.3.1) described by Skamarock et al. (2008) and the CReSS developed by the Hydrospheric Atmospheric Research Center (HyARC) of Nagoya University, Japan (Tsuboki and Sakakibara 2007). For simulation of the given case in this study, we set up the standard versions of both models without specific modification. Here, we provide the minimum explanation of each model, and further details appear in the references addressed in this section.

The WRF model is a next-generation meso-scale numerical weather prediction system designed to serve both operational forecasting and atmospheric research needs. The Advanced Research WRF solver developed at the National Center for Atmospheric Research was used for the dynamic core, which is a fully compressible and non-hydrostatic model. The physical parameterizations include the 5-layer thermal diffusion land-surface model (Chen and Dudhia 2001), the Yonsei University (YSU) planetary boundary layer scheme (Hong et al. 2006), the Rapid Radiative Transfer Model (RRTMG) longwave radiation scheme (Malwer et al. 1997; Iacono et al. 2008), Goddard shortwave radiation scheme (Tao et al. 1989), the Double-Moment (WDM) 6-class microphysics scheme (Lim and Hong 2010) and none cumulus parameterization scheme. We selected this combination of the physical schemes based on previous studies to optimize the WRF performance over the domain, including the Korean peninsula throughout various sensitivity experiments (e.g., Hong and Lee 2009; Lim and Hong 2010; Cho and Lee 2006).

The CReSS is a three-dimensional model with a fully compressible and non-hydrostatic dynamics, as well. Planetary boundary layer (PBL) processes are parameterized largely following Mellor and Yamada (1974). The microphysics processes are formulated by a bulk method of cold rain (Murakami et al. 1994). Subgrid-scale turbulent mixing was parameterized by 1.5 order closure with a turbulent kinetic energy prediction (Tsuboki and Sakakibara 2002, 2007; Lee et al. 2010).

Both models were performed under the same experiment design. The model domain focused on the southern part of the Korean peninsula. A total of 30 vertical levels were employed, while the horizontal resolution was $2 \mathrm{~km}$ with 330 (North-South direction) $\times 330$ (East-West direction) grid points and the central point was located at $35.5^{\circ} \mathrm{E}$ and $127^{\circ} \mathrm{N}$. Integration spanned the 24-h period from 2100 UTC on September 20, 2010. The initial and lateral boundary conditions were interpolated from the output of the mesoscale model of JMA with 5-km-horizontal resolution at 3-h intervals.

\section{Observational synoptic condition and general characteristics}

We begin our analysis with a discussion on the synoptic overview from the weather chart. Prior to the analysis of the model results, it is important to examine the observed threedimensional structures which are responsible for building a favorable environment for convection accompanying heavy rainfall. It might provide the first glance for understanding what can be control parameters to determine the model performance. 
Figure 1 shows the surface, 850 and $200 \mathrm{hPa}$ synoptic weather chart at 0000 UTC September 21, 2010 when the rainfall started. These synoptic patterns exhibited almost similar features during the integration period. At surface, a well-developed continental High over northern China to the northwest of the Korean peninsula was faced with a northwestern Pacific High to the southeast of the Korean peninsula. The Korean peninsula was located between them, so that an elongated trough intersected over the peninsula. Such a synoptic pattern is a favorable ingredient for heavy rainfall over the Korean peninsula because cold advection from northern China and warm advection from near the subtropical Pacific High build up strong baroclinicity, leading to the formation of the stationary front spanning over the mid-peninsula. In addition, a tropical depression (TD) developing in the subtropical western Pacific appears to have contributed to the supply of moisture to Korea along the northwestern flank of the northwestern Pacific High. Moving to $850 \mathrm{hPa}$, the humid area (green dot), which is defined as dew-point depression was less than $3{ }^{\circ} \mathrm{C}$, is broadly distributed across the whole Korean peninsula, which implies the presence of a moisture convergence zone due to inflow of warm and humid air from the subtropical western Pacific. In addition, the TD (later developing to typhoon Malakas) in the subtropical western Pacific is moving to the northward, thus pushes the northwestern Pacific High farther north which can contribute to enhance the moisture advection and to hinder the shrink of the northwestern Pacific High. Strong temperature gradient observed in over Bohai also appears to stir up the instability for convection. At $200 \mathrm{hPa}$, the strong polar jet is zonally prevailing along $40^{\circ} \mathrm{N}$. The divergence in the upper troposphere accelerates the low level convergence, which dynamically induces the ascent of the warm and moisture air.

The aforementioned synoptic condition attempts to activate the cloud formation. Satellite imagery (MTSAT IR) clearly shows the propagation of the convection band (Fig. 2). The convection band started to develop over the Yellow Sea and coastal area near the mid-peninsula around 0000 UTC 21 September. It continuously moved eastward maturing its extent and strength (about 0600 UTC), which accompanied heavy rainfall along a narrow area. As a result of the quasi-stationary behavior of the convection band for several hours and the continued passage of convection cells along the band, the rainfall became concentrated in a narrow zone and produced a large accumulation of rainfall along the band. This behavior caused several record-breaking values such as a daily accumulated rainfall amount $(259.5 \mathrm{~mm})$ and a maximum hourly rain rate $(75 \mathrm{~mm})$ in Seoul.

\section{Results}

To estimate the CReSS and WRF performance in simulating this rainfall event, we compared the characteristics of the rainfall derived from the both simulations with observed one. The observational data used to validate the model were composed of 74 Automated Surface Observing Systems (ASOS) and 581 Automatic Weather Stations (AWS) maintained by KMA. Combining the ASOS and AWS stations gave 655 locations relatively evenly distributed with fine-scale spatial variability.

Figure 3 presents the spatial distribution of 24-h accumulated rainfall (2100 UTC 20-2100 UTC 21) as well as three 1-h accumulated rainfall during the mature period (0600, 0800, 1000 UTC 21). Regarding the 24-h accumulated rainfall, the CReSS simulation successfully captured the observed general pattern of the rainfall with an elongation along the middle of the Korean peninsula and a maximum rainfall located in the mid-west, whereas the WRF showed less skillful performance in capturing the intensity and location 


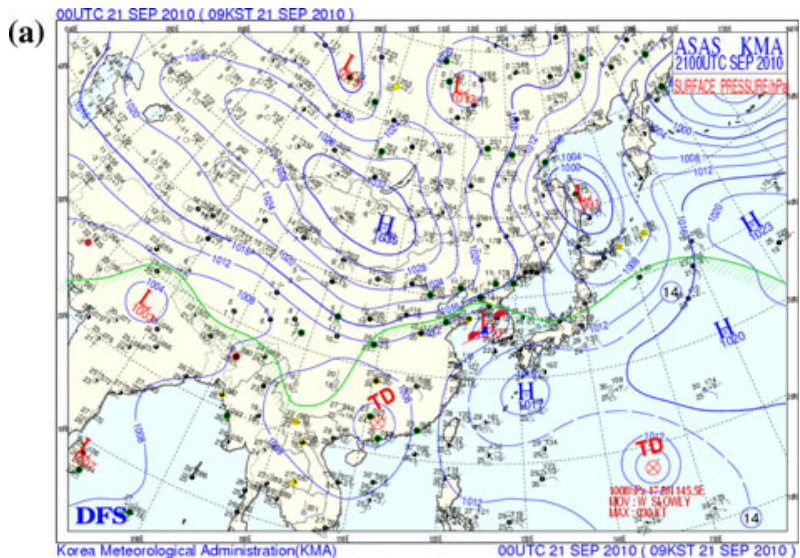

(b)
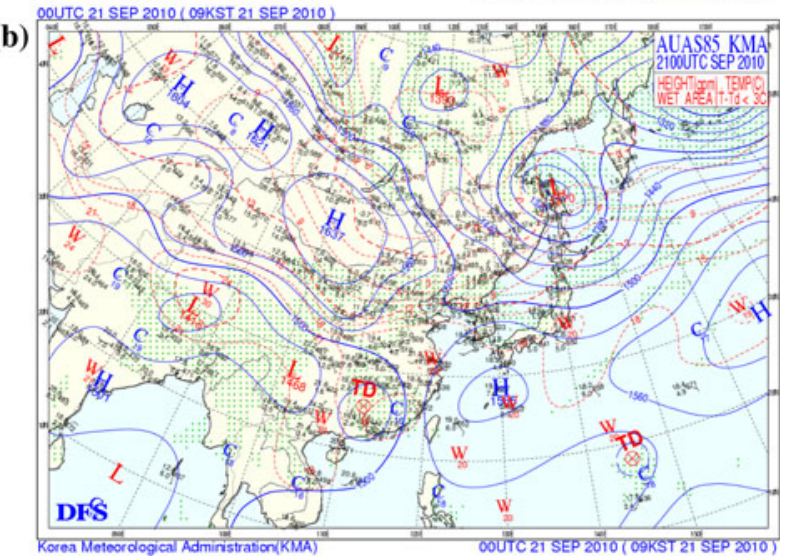

(c)

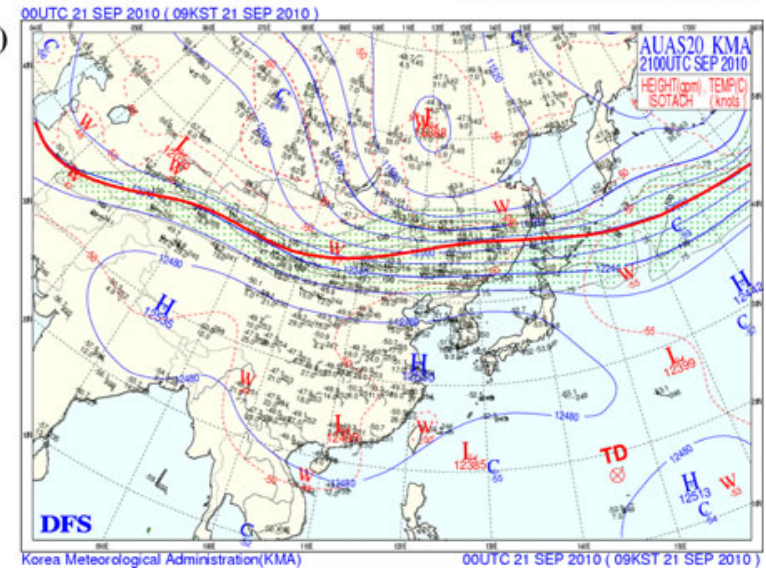

Fig. 1 Surface (a), $850 \mathrm{hPa}(\mathbf{b})$ and $200 \mathrm{hPa}$ (c) synoptic weather chart at 0000 UTC September 21, 2010. Here, blue line and red dotted line indicate the isobaric and isothermal line, respectively. Green deviant crease line of (a) indicates the precipitation area while green dot of (b) indicates the humid area defined as dew-point deviation was $<3{ }^{\circ} \mathrm{C}$. Red thick line of $(\mathbf{c})$ indicates the jet stream axis with maximum wind speed 

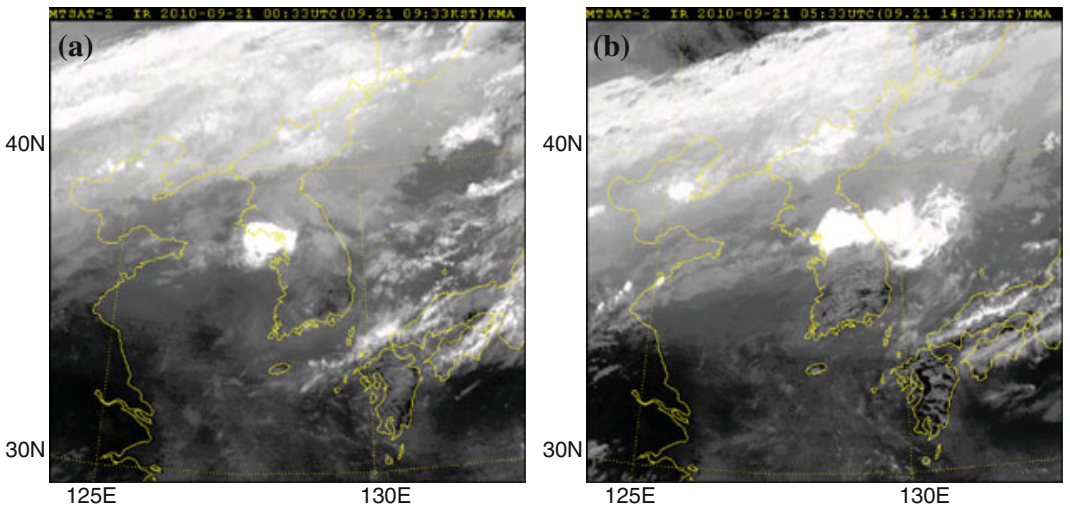

Fig. 2 MTSAT IR images at 0033 UTC 21 (a) and 0533 UTC 21 (b) September 2010
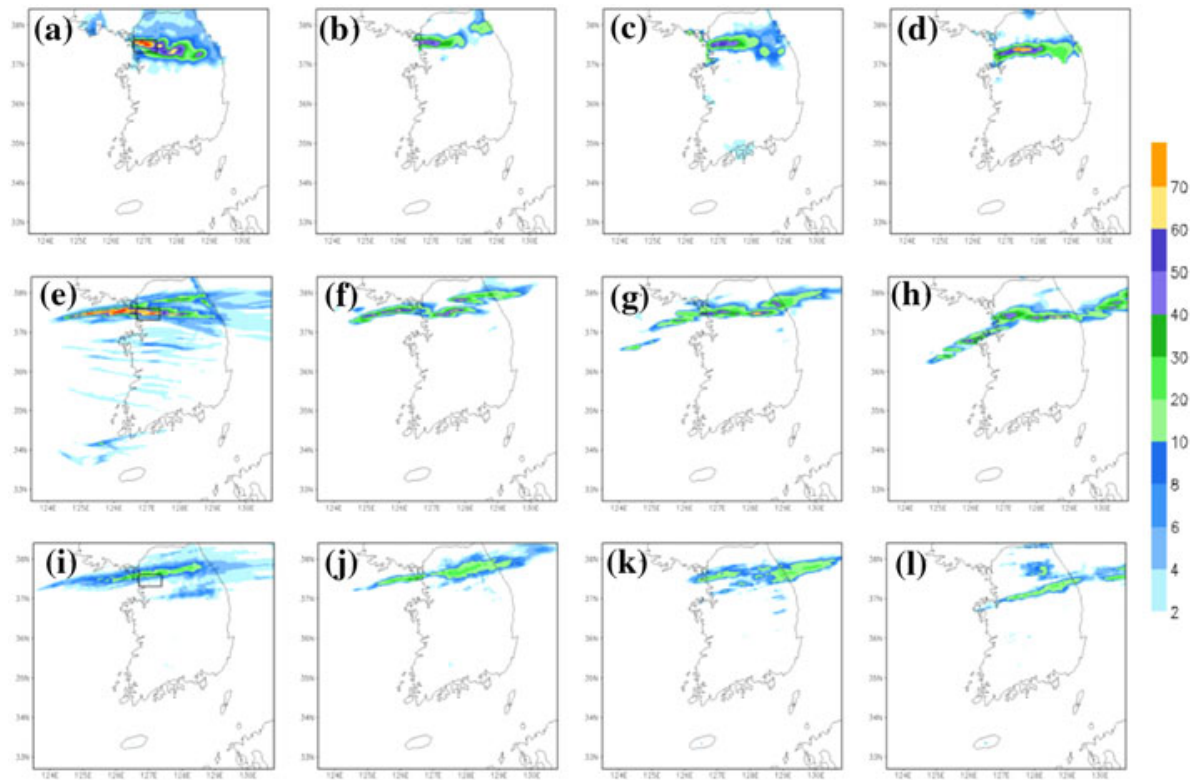

Fig. 3 Spatial distribution of 24-h accumulated rainfall (a, e, i) and 1-h accumulated rainfall during mature stage of convection band (b, f, $\mathbf{j}$ for $0600, \mathbf{c}, \mathbf{g}, \mathbf{k}$ for $0800, \mathbf{d}, \mathbf{h}, \mathbf{l}$ for 1000 UTC 21) derived from the observation (upper panels), CReSS (middle panels) and WRF (lower panels) simulations

of maximum rainband passing through the rectangular box. Such a deficiency in the WRF simulation is also observed at each hour rainfall pattern during the mature period. The observation tends to maintain strong rainband slowly propagating toward inland; therefore, at $1000 \mathrm{UTC}$ rainband, more than $60 \mathrm{~mm} \mathrm{~h}^{-1}$ intensity is still stagnant. On the other hand, the rainband simulated by the WRF became quickly week and mostly disappeared in the west middle of the peninsula at 1000 UTC. 


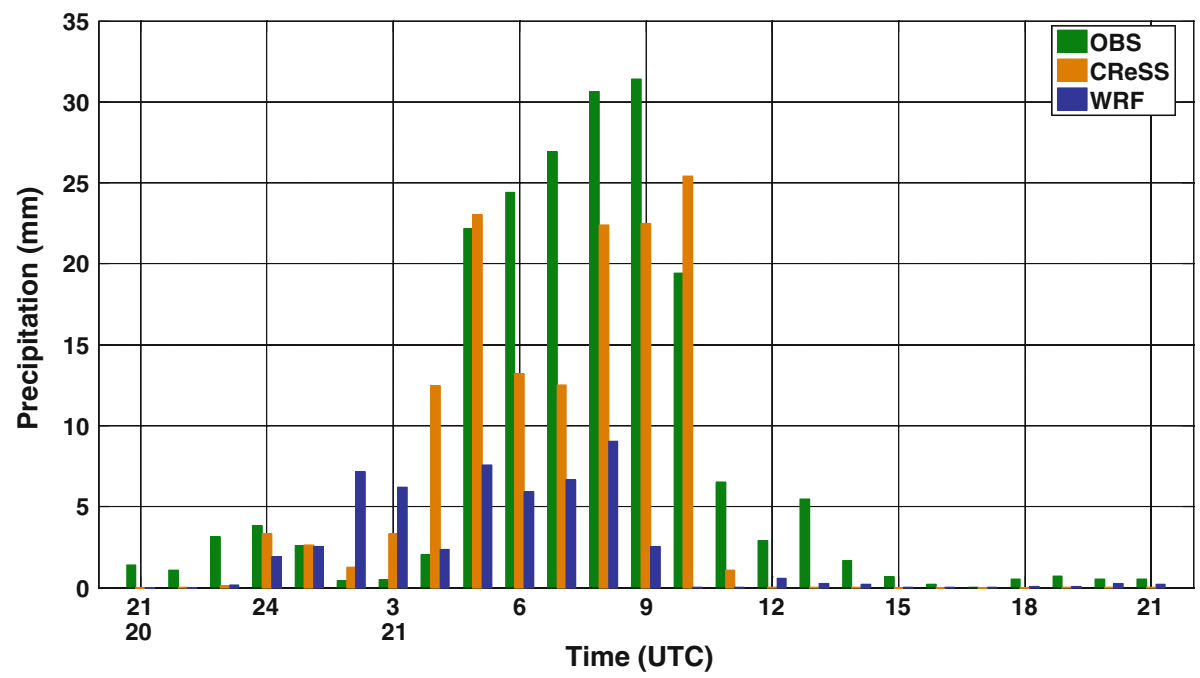

Fig. 4 Time series of 1-h accumulated rainfall averaged over the rectangular area as shown in Fig. 3

Relative strength and weakness of both simulations become more pronounced in the temporal evolution of rainfall. Figure 4 presents the time-series of 1-h accumulated rainfall averaged over heavy rainfall area, including the Seoul location hit by record-breaking values derived from the observation and both model simulations (the black rectangular box in Fig. 3, Lon: 126.7-127.4 and Lat: 37.3-37.6). First, the observed pattern reveals abrupt phase transition such as growth, mature and decay. The rainfall remaining below $5 \mathrm{~mm} \mathrm{~h}^{-1}$ until 0400 UTC 21 suddenly goes up more than $20 \mathrm{~mm} \mathrm{~h}^{-1}$, and mature phase persists during approximately $6 \mathrm{~h}$, subsequently weakens and decays. Stagnant feature maintaining relatively long mature period is one of the relevant behavior of this event, causing severe damage due to flash flooding. Moving to the model performance how to capture such observed features, both models worked on the temporal evolution of rainfall in fairly different way even though the same large-scale forcings were provided as the initial and lateral boundary conditions. The WRF shows the limitation in not only quantitative underestimation but also evolutionary feature. The WRF seemed to produce the shifted temporal phase, showing the earlier starting and the earlier ending. There is the mature period lasting several hours, but the corresponding intensities are inferior to onethird of observed one. Even though the CReSS also reveals the deficiency in its performance, the phase coherence and quantitative aspect are in better agreement with observed ones. During the peak period, the maximum 1-h rainfall amount close to $25 \mathrm{~mm}$ was an encouraging performance that demonstrated the possible capability of CReSS for simulating heavy rainfall. The correlation coefficients in temporal evolution of CReSS and WRF with observation are 0.88 and 0.60 , respectively, reflecting the better performance of CReSS.

In order to investigate the development of the mesoscale convective system mainly responsible for the heavy rainfall, we provide the spatial distribution of reflectivity derived from the observation and two simulations during the mature period $(0600,0800,1000$ UTC 21) (Fig. 5). The calculation algorithm of reflectivity in both models is based on the function of density, rain water, snow and graupel mixing ratio, while the observation is estimated using the composite Doppler radar data from the five different radars operated by 

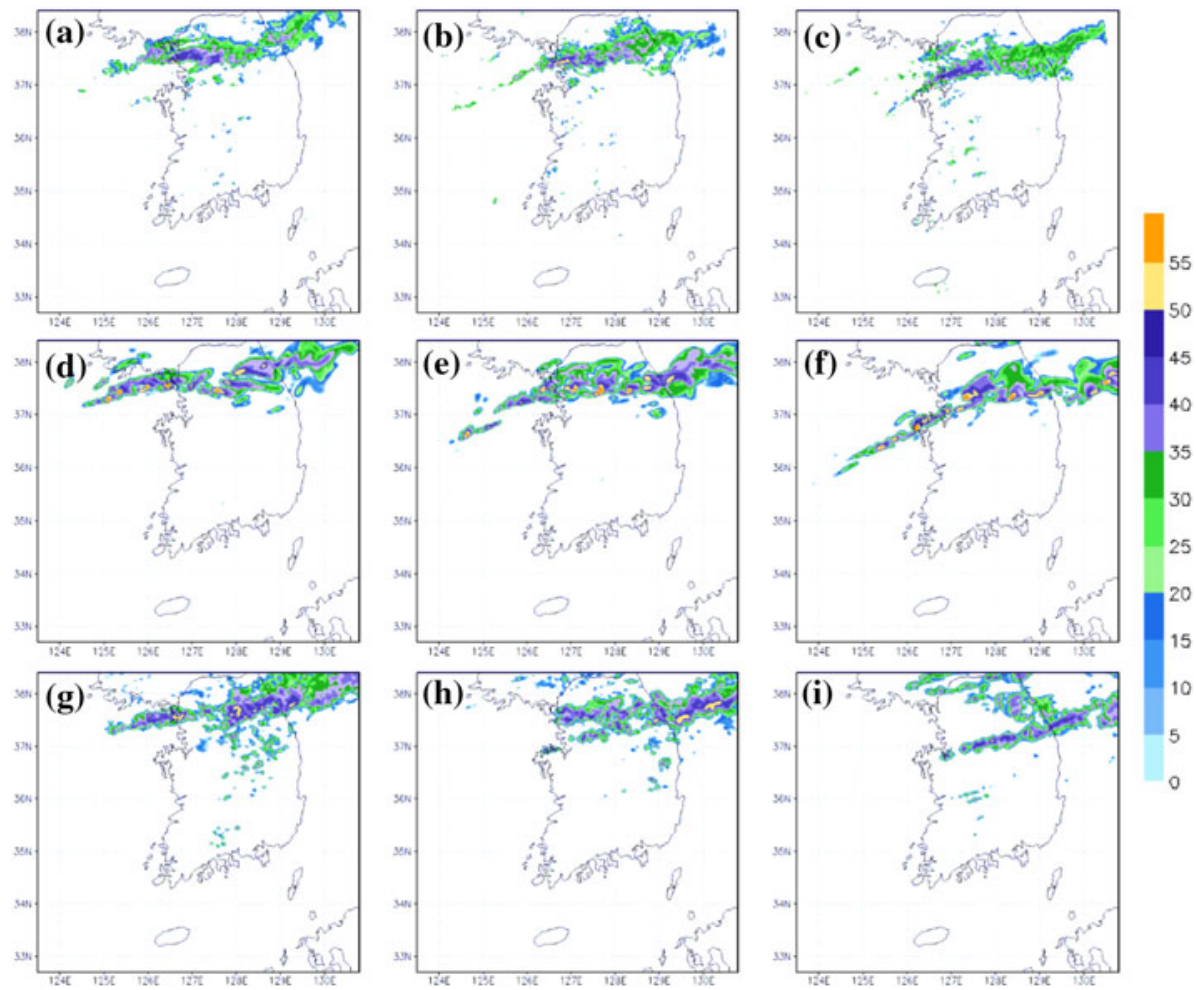

Fig. 5 Spatial distribution of reflectivity during mature stage of convection band (a, d, $\mathbf{g}$ for 0600 , b, e, $\mathbf{h}$ for $0800, \mathbf{c}, \mathbf{f}, \mathbf{i}$ for 1000 UTC 21) derived from the observation (upper panels), CReSS (middle panels) and WRF (lower panels) simulations

KMA. By comparison, the spatial pattern and evolution behavior of reflectivity seem to mirror those of the rainfall. Generally, reflectivity greater than $45 \mathrm{dBz}$ is considered as strong convective region (Lee et al. 2010). In fact, the distribution of the convective cloud shown in the satellite IR imagery (Fig. 2b) is similar with that of the observed reflectivity at 0600 UTC (Fig. 5a). In both simulations, the regions of strong reflectivity are also consistent with the heavy rainfall distribution, which enables the main cause of rainfall deficiency appearing in each model to be determined in association with the reflectivity characteristics. While the localized strong reflectivity stagnated in the middle of the peninsular until 1000 UTC in the observation and CReSS simulation, the WRF tends to decay early and move rapidly eastward. Therefore, the WRF tends to be less skillful in capturing the stagnant behavior that is the most relevant feature of this event, compared to the CReSS simulation.

For more in-depth analysis of reflectivity, we examine the vertical-time cross sections of reflectivity averaged over the rectangular, as shown in Fig. 3 (Fig. 6). The enhancement and dissipation processes of the convection activity are not limited in the low boundary layer, but also affected in the echo-top height. A strong convective cell with a height exceeding $9 \mathrm{~km}$ during the peak time is shown in the observed structure and has a shape of a bimodal distribution. The corresponding model simulations do not well capture such a strong echo missing the exact timing and intensity of each convective cell. The CReSS 

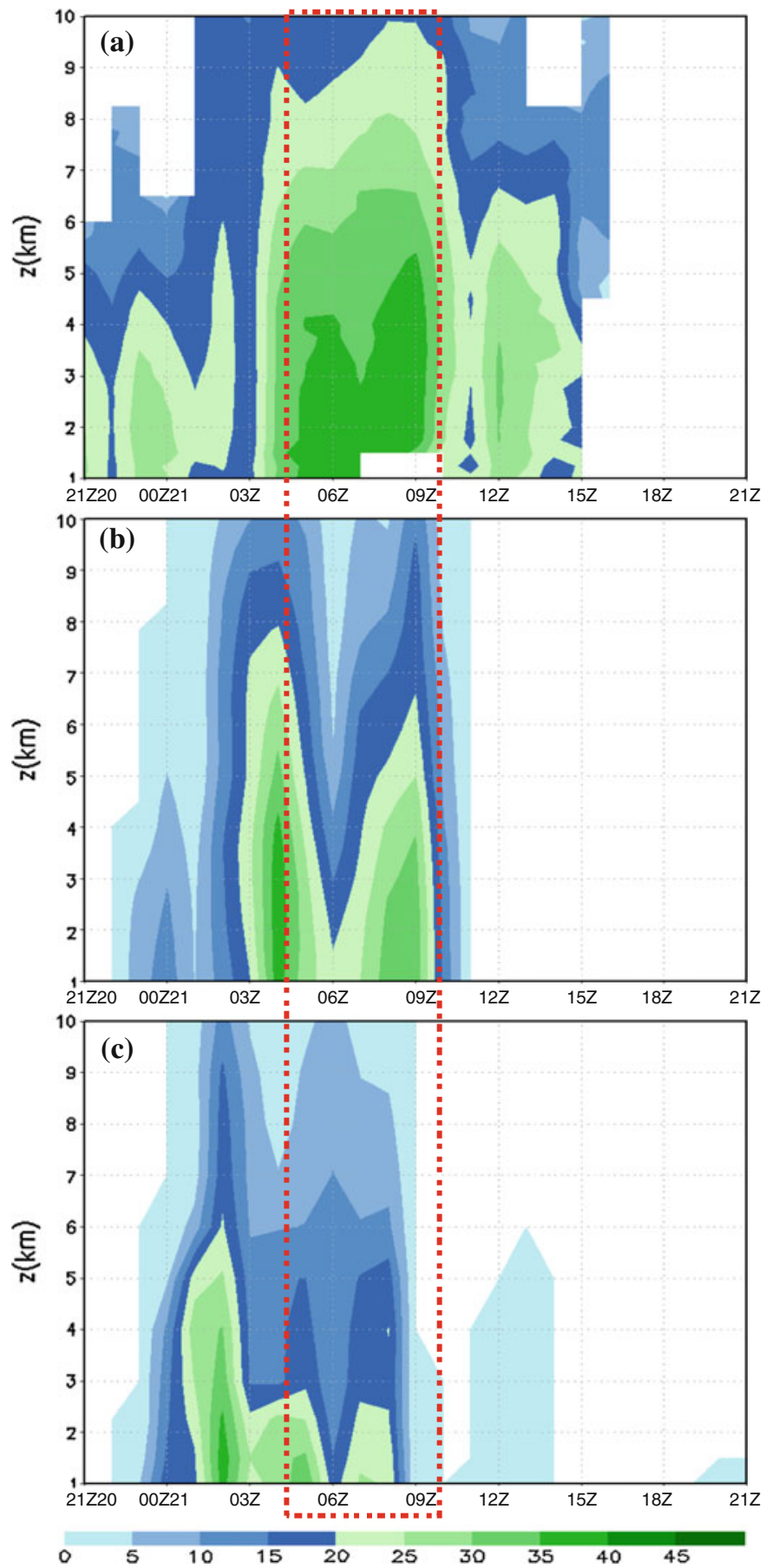

Fig. 6 Vertical-time cross section of reflectivity averaged over the rectangular area as shown in Fig. 3. Upper, middle and lower panels are from observation (a), CReSS (b) and WRF (c) simulations, respectively. Here, dotted red box includes the mature period (0500-1000 UTC) 

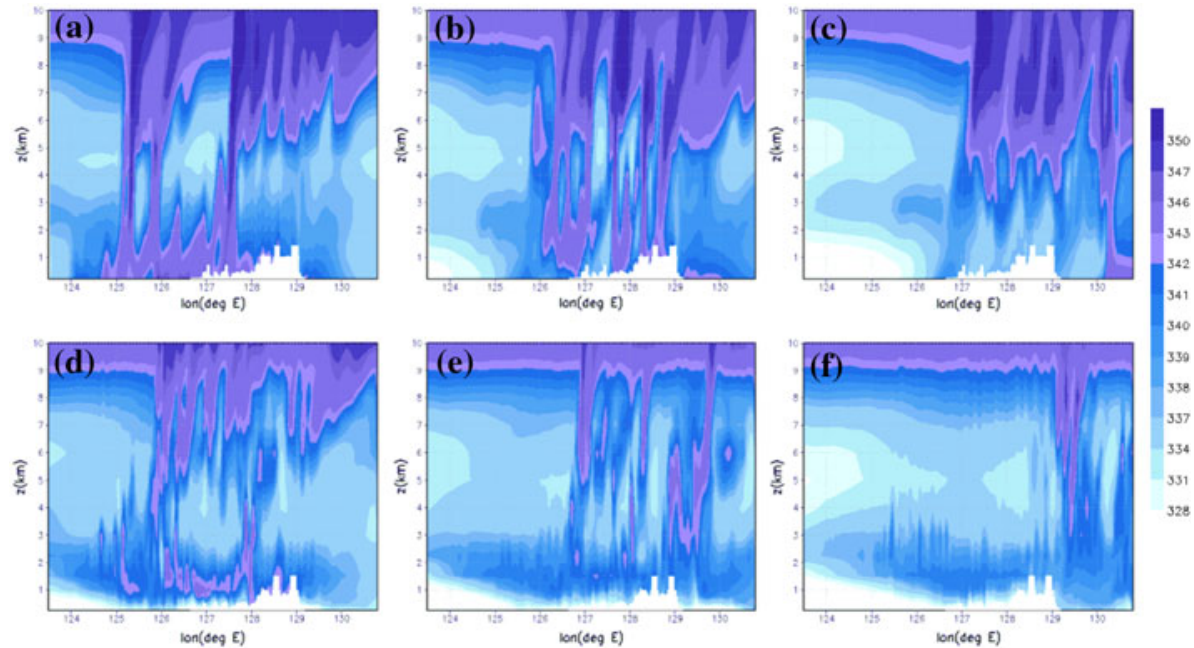

Fig. 7 Vertical cross section of equivalent potential temperature during mature stage of convection band (a, d for 0600, b, e for 0800, c, f for 1000 UTC 21) derived from CReSS (upper panels) and WRF (lower panels) simulations

simulation appears to follow the bimodal feature, but the timing of the first distinct cell has shifted to earlier, thereby appearing out of red dotted box, and the magnitude of the successively developing cell decreased and the echo-top height reduced. In the WRF simulation, the maximum convective cell is entirely shifted. The limitation in which the convective activity matured too early and thereby weakened too early is again exposed in the vertical structure of reflectivity. In spite of both models' discrepancy with observed behavior, these results overall suggest that the CReSS shows better agreement in magnitude and timing.

The processes regulating such divergent behavior between the two models are very complex and not easily measured because they operated under different physical parameterizations. Nevertheless, one possible explanation can be postulated: the different circumstances of the thermodynamic structure. Figure 7 presents the vertical distribution of equivalent potential temperature along the longitude at $37.45^{\circ} \mathrm{N}$ latitude (center of rectangular box in Fig. 3) simulated by CReSS and WRF. The higher equivalent potential temperature in the lower levels could be an indication of potential instability responsible for convectively favorable environment. The intense unstable region demonstrates an eastward movement in both simulations. However, the increase of vertical equivalent potential temperature at the lower level seems to be strengthened in the CReSS simulation. In conjunction with the equivalent potential temperature, the CReSS shows a stronger ascending motion compared to that of WRF in the distribution of vertical velocity at $850 \mathrm{hPa}$ (not shown). The strong ascending motion can contribute to transport the high potential temperature to the upper atmosphere during the development of the convection cell.

In order to confirm that the CReSS produced a moister and more unstable environment for convection, we examine the skew $\mathrm{T}-\log \mathrm{p}$ diagram representing the thermodynamic profile (Fig. 8). Such a sounding profile could be a useful tool to determine the stability by comparing the slope of temperature and dew-point temperature curves. Both simulations 
form a markedly different thermodynamic structure. The first major difference between both simulations is that only CReSS generated the moist absolutely unstable layer (MAUL) proposed by Bryan and Fritsch (2000). Above the unsaturated boundary layer, there is a 400-mb deep MAUL (from 800 to $400 \mathrm{mb}$ ) in the simulated sounding of the CReSS, and the almost complete saturation of this layer reveals $100 \%$ relative humidity. All parcels in this saturated layer are unstable at any displacement because the saturated lapse rate is greater than the moist adiabatic lapse rate. Many references based on the analysis of both observations and simulations suggest that the existence of MAUL is evidence of strong convective activity (Choi et al. 2011). When looking at the convective available potential energy (CAPE), the values from both simulations were not as large as the typical magnitude that is required to develop an environment conducive for the convective storm (e.g., CAPE > 1000, Djuric 1994; Weisman and Klemp 1982; Rasmussen and Blanchard 1998). This indicates that the saturated and unstable environment seen in both simulations is not critically dependent on the buoyant energy available to accelerate a parcel vertically. In particular, the profile of CReSS simulation clearly shows that the lapse rate of temperate seems to follow closely the moist adiabatic lapse rate through most of MAUL, and thus, the temperature curve is mostly parallel to a moist adiabat. Since it implies statically neutral condition, it is rather difficult to explain that the atmospheric instability of the simulation is induced by effectively positive buoyancy of a rising air parcel. Under the similar circumstance with our case, several studies have reported that the mesoscale convective system was developed under highly baroclinic environments without higher CAPE over Korea (Choi et al. 2011). Moving to the hodograph reflecting the veering of the wind with height, the two simulations generated different magnitude and direction of veering wind. The CReSS showed stronger wind magnitude and reversal of shear with height. This different behavior clearly reflected the storm-relative environmental helicity (SREH), which is shown to be a measure of the potential for updraft rotation in a storm (Blanchard 2011; Davies-Jones et al. 1990). The SREH (126 $\mathrm{m}^{2} \mathrm{~s}^{-2}$, negative sign-turning counterclockwise) produced by CReSS is much higher than that of WRF $\left(19 \mathrm{~m}^{2} \mathrm{~s}^{-2}\right)$ and is actually above the median for the criteria of the convective supercell classified by Rasmussen and Blanchard (1998). Therefore, CReSS formed a more favorable environment for upward advection of warm and moist air at the lower level. Based on the sounding analysis, the existence of MAUL and the stronger veering wind shear plays important roles in maintaining the convective system rather than the increased buoyant instability.

\section{Summary and discussion}

In this study, we explored and compared the ability of the Weather Research and Forecasting (WRF) and Cloud Resolving Storm Simulator (CReSS) to simulate a quasi-stationary convection band accompanying heavy rainfall. As a case study, we attempted to simulate the heavy rainfall caused by the convection band on September 21, 2010, which brought tremendous damage in the middle of the Korean peninsula. In our experiments, the domain focused on the southern part of Korea with $2 \mathrm{~km}$ high resolution. Integration spanned $24 \mathrm{~h}$ from 2100 UTC on September 20, 2010 using the output of the mesoscale model of JMA as the initial and lateral boundary conditions.

The selected target event was classified as a typical rainfall pattern due to the intense quasi-stationary convection band. A favorable synoptic condition for promoting the convective instability appeared around the Korean peninsula. The dry and cold continental High was confronted with a moist and warm northwestern Pacific High between the 

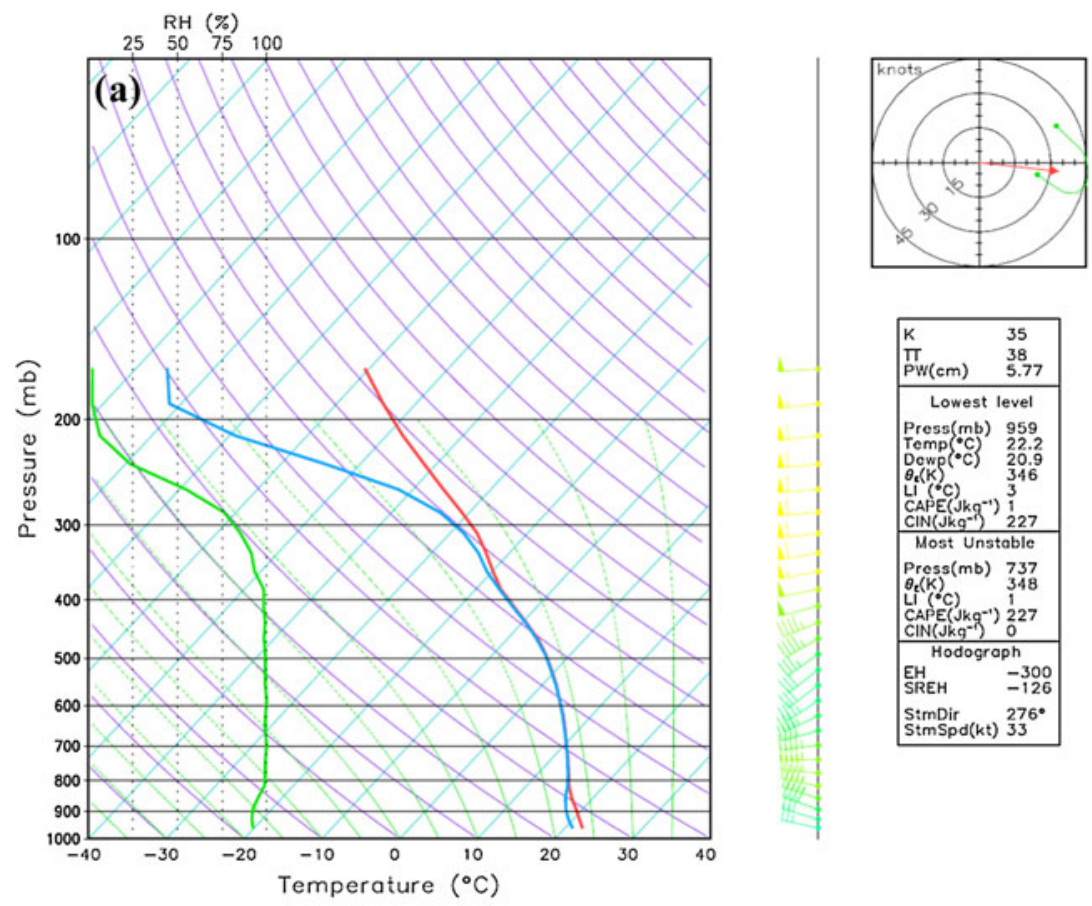

\begin{tabular}{|c|c|}
\hline $\begin{array}{l}{ }_{P}^{K} \\
P W(\mathrm{~cm})\end{array}$ & $\begin{array}{l}35 \\
38 \\
5.77\end{array}$ \\
\hline \multicolumn{2}{|c|}{ Lowest level } \\
\hline 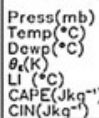 & $\begin{array}{l}959 \\
22.2 \\
20.9 \\
346 \\
3 \\
1 \\
227\end{array}$ \\
\hline \multicolumn{2}{|c|}{$\frac{\text { Most Unstable }}{\text { Most }}$} \\
\hline 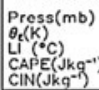 & $\begin{array}{l}737 \\
348 \\
1 \\
227 \\
0\end{array}$ \\
\hline \multicolumn{2}{|c|}{ Hodograph } \\
\hline $\begin{array}{l}\text { EH } \\
\text { SREH }\end{array}$ & $\begin{array}{l}-300 \\
-126\end{array}$ \\
\hline $\begin{array}{l}\text { StmDir } \\
\text { StmSpd(k }\end{array}$ & $33^{276^{\circ}}$ \\
\hline
\end{tabular}
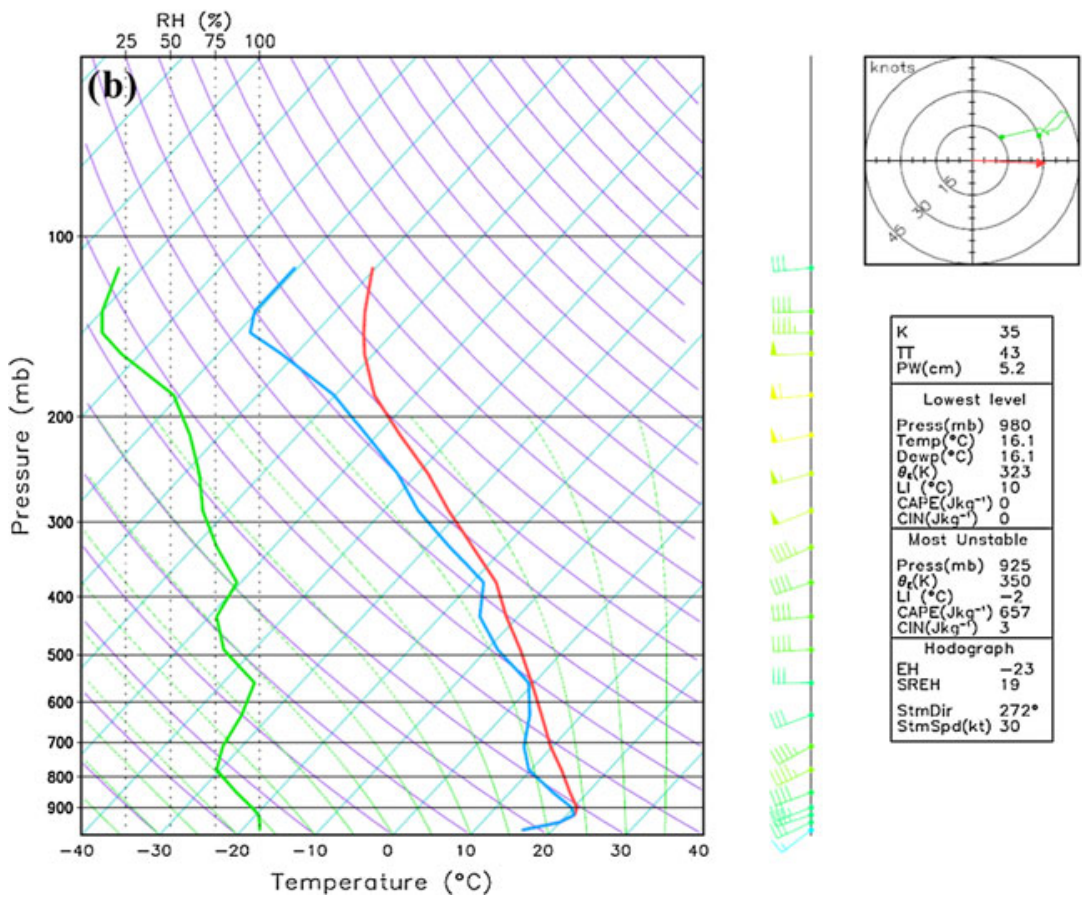

\begin{tabular}{|c|c|}
\hline $\begin{array}{l}\mathrm{K} \\
\prod_{\mathrm{PW}(\mathrm{em})}\end{array}$ & $\begin{array}{l}35 \\
43 \\
5.2\end{array}$ \\
\hline \multicolumn{2}{|c|}{ Lowest level } \\
\hline 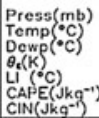 & $\begin{array}{l}980 \\
16.1 \\
16.1 \\
323 \\
10 \\
00 \\
0\end{array}$ \\
\hline \multicolumn{2}{|c|}{ Most Unstable } \\
\hline 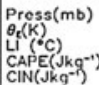 & $\begin{array}{r}925 \\
350 \\
-2 \\
657 \\
3\end{array}$ \\
\hline \multicolumn{2}{|c|}{ Hodograph } \\
\hline EH & -23 \\
\hline $\begin{array}{l}\text { S:mDir } \\
\text { StmSpd(kt) }\end{array}$ & $272^{\circ}$ \\
\hline
\end{tabular}

Fig. 8 Skew T-log p diagram at Seoul location 06 UTC 21 September derived from CReSS (a) and WRF (b) simulations. Here, red, blue and green lines indicate temperature, dew-point temperature and humidity, respectively 
Korean peninsula, which built up strong baroclinicity throughout the conflict between the cold advection and the warm advection. The convection cell that started to develop over the Yellow Sea and coastal area near the mid-peninsula around 0000 UTC on 21 September continuously propagated eastward forming a long and narrow band. Both simulations appeared to capture the basic characteristics of rainfall in terms of spatial distribution and temporal evolution; however, they show rather different performance against detailed in situ observations. By comparison, the WRF simulation revealed more quantitative and qualitative discrepancy with observed estimation, showing less rainfall and shifted phase during the peak time. On the other hand, the CReSS simulation relatively well captured the location and intensity of the maximum rainfall. Phase coherency in rainfall temporal evolution was also in better agreement with observed pattern than that of WRF simulation. The spatial and vertical structure of the reflectivity gives us the hint of the discrepancy between observed and simulated rainfall. The vertical cross section of the reflectivity derived from the WRF simulation showed much lower echo height of convective cell and too advanced development, reflecting the shifted phase. The main reason to bring different behavior in rainfall and convective activity between both simulations can be found in the thermodynamic structure. Existence of MAUL and higher equivalent potential temperature in the CReSS simulation tend to form more saturated and unstable environment, which are directly linked to the promotion of the convective behavior. In addition, the strong veering wind shear (as described by the higher SREH) also contributes to a more favorable environment for convection through upward advection of warm and moisture air.

Considering the large error of the forecasted rainfall amount from several operational numerical modeling systems (e.g., KMA, ECMWF, etc.), the CReSS performance in simulating a daily accumulated rainfall amount of approximately $181 \mathrm{~mm}$ and maximum hourly rain rate of $40 \mathrm{~mm}$ in Seoul is encouraging, although these values remained underestimated. The objective of this paper is not to confirm the superiority of CReSS over WRF and other modeling systems, but rather to demonstrate its potential utilization for the Korean region, in particular for the heavy rainfall caused by the convection band for which the cloud resolving process is the most important factor. Furthermore, the comparison of both simulations is necessarily limited in scope and aims since the dynamic core and physical parameterizations implemented by both models are not identical.

Given that the characteristics of simulated rainfall strongly depend on the models even though the same initial and boundary conditions are used, our results suggest that a multimodel ensemble is necessary for more accurate prediction of heavy rainfall. We can also find the possibility that the high-resolution non-hydrostatic model is capable of predicting the heavy rainfall caused by a convection bands. Ultimately, it will contribute to disaster prevention due to heavy rainfall in the areas of the present study. To derive a more robust statement, we are going to prepare the simulations of both models using different initial and boundary conditions (e.g., the Korea Local Analysis and Prediction System, KLAPS). Since the mesoscale model is strongly dependent upon the lateral boundary condition, accurate comparison between the CReSS and WRF simulations under the various boundary conditions will help objectively estimate their performances. In addition, further study should be expanded with many case experiments including various location and period of maximum rainfall and different underlying mechanism, which help improve our understanding of model behaviors.

Acknowledgements. This work was supported by a Grant (NIMR-2012-B-7) funded by the National Institute of Meteorological Research (NIMR), the Korea Meteorological Administration (KMA). The weather charts and observation data are provided by KMA, which should be acknowledged. The authors are 
also grateful to Prof. Tsuboki and his research group who kindly provided the CReSS model and some technical support for the model setup. Finally, comments by two anonymous reviewers are appreciated for improving the original manuscript.

Open Access This article is distributed under the terms of the Creative Commons Attribution License which permits any use, distribution, and reproduction in any medium, provided the original author(s) and the source are credited.

\section{References}

Blanchard DO (2011) Supercells in environments with atypical hodographs. Weather Forecast 26: 1075-1083

Bryan GH, Fritsch JM (2000) Moist absolute instability: the sixth static stability state. Bull Am Meteorol Soc 81:1207-1230

Chen F, Dudhia J (2001) Coupling and advanced Land surface-hydrology model with the Penn State-NCAR MM5 modeling system. Part: model implementation and sensitivity. Mon Weather Rev 129:569-585

Chen SJ, Lee DK, Tao ZY, Kuo YH (1999) Mesoscale convective system over the yellow sea-a numerical case study. Meteorol Atmos Phys 70:185-199

Cho NS, Lee TY (2006) A numerical study of multiple convection bands over the Korean peninsula. J Korean Meteorol Soc 42:87-105

Choi HY, Ha JH, Lee DK, Kuo YH (2011) Analysis and simulation of mesoscale convective system accompanying heavy rainfall: the Goyang case. Asia Pac J Atmos Sci 47:265-279

Davies-Jones RP, Burgess D, Foster M (1990) Test of helicity as a tornado forecast parameter. Preprints 16th conference on severe local storms, Kananaskis Park, AB Canada. Am Meteorol Soc 588-592

Djuric D (1994) Weather analysis. Prentice Hall, Englewood Cliffs

Hong SY, Lee JW (2009) Assessment of the WRF model in reproducing a flash-flood heavy rainfall event over Korea. Atmos Res 93:818-831

Hong SY, Noah Y, Dudiha J (2006) A new vertical diffusion package with an explicit treatment of entrainment processes. Mon Weather Rev 134:2318-2341

Iacono MJ, Delamere J, Mlawer E, Shephard M, Clough S, Collins W (2008) Radiative forcing by longlived greenhouse gases: calculations with the AER radiative transfer models. J Geophys Res 113: D13103. doi:10.1029/2008JD009944

Kim HW, Lee DK (2006) An observational study of mesoscale convective system with heavy rainfall over the Korean peninsula. Weather Forecast 21:125-148

Lee TY, Kim YH (2007) Heavy precipitation systems over the Korean peninsula and their classification. J Korean Meteorol Soc 43:367-396

Lee KO, Shimizu S, Maki M, You CH, Uyeda H, Lee DI (2010) Enhancement mechanism of the 30 June 2006 precipitation system observed over the northwestern slope of Mt. Halla, Jeju Island, Korea. Atmos Res 97:348-358

Lim KSS, Hong SY (2010) Development of an effective double-moment cloud microphysics scheme with prognostic cloud condensation nuclei $(\mathrm{CCN})$ for weather and climate models. Mon Weather Rev 138:1587-1612

Malwer EJ, Taubman SJ, Brown PD, Iacono MJ, Clough SA (1997) Radiative transfer for on-homogeneous atmospheres: RRTM, a validated correlated-k model for the longwave. J Geophys Res 102: 16663-16682

Mellor GL, Yamada T (1974) A hierarchy of turbulent closure models for planetary boundary layers. J Atmos Sci 31:1791-1806

Murakami M, Clark TL, Hall WD (1994) Numerical simulations of convective snow clouds over the sea of Japan; two-dimensional simulations of mixed layer development and convective snow cloud formation. J Meteorol Soc Jpn 72:43-62

Rasmussen EN, Blanchard DO (1998) A baseline climatology of sounding-derived supercell and tornado forecast parameters. Weather Forecast 13:1148-1164

Shin CS, Lee TY (2005) Development mechanisms for the heavy rainfalls of 6-7 August 2002 over the middle of the Korean peninsula. J Meteorol Soc Jpn 83:683-709

Skamarock WC et al (2008) A description of the advanced research WRF version 3. NCAR Tech Note NCAR/TN-475+STR, pp 125

Sun J, Lee TY (2002) A numerical study of an intense quasi-stationary convection band over the Korean peninsula. J Meteorol Soc Jpn 80:1221-1245 
Tao WK, Simpson J, McCumber M (1989) An ice-water saturation adjustment. Mon Weather Rev 117:231-235

Tsuboki K, Sakakibara A (2002) Large-scale parallel computing of cloud resolving storm simulator. In: Zima HP et al (eds) High performance computing. Springer, Berlin, pp 243-259

Tsuboki K, Sakakibara A (2007) CReSS user's guide. Available from http://www.rain.hyarc.nagoya-u.ac.jp/ $\sim$ tsuboki/cress_html/src_cress/CReSS2223_users_guide_eng.pdf

Weisman ML, Klemp JB (1982) The dependence of numerically simulated convective storms on vertical wind shear and buoyancy. Mon Weather Rev 110:504-520

Yu X, Lee TY (2010) Role of convective parameterization in simulations of a convection band at grey-zone resolutions. Tellus 62A:617-632 